\title{
Identification of FDA-Approved Drugs and Bioactives that Protect Hair Cells in the Zebrafish (Danio rerio) Lateral Line and Mouse (Mus musculus) Utricle
}

\author{
Henry C. Ou ${ }^{1,2,4}$, Lisa L. Cunningham ${ }^{5}$, Shimon P. Francis ${ }^{5}$, Carlene S. Brandon ${ }^{5}$, Julian A. Simon ${ }^{6}$, \\ David W. Raible ${ }^{1,3}$, AND EDWIn W Rubel ${ }^{1,2}$ \\ ${ }^{1}$ Virginia Merrill Bloedel Hearing Research Center, University of Washington, Box 357923 Seattle, WA 98195, USA \\ ${ }^{2}$ Department of Otolaryngology-Head and Neck Surgery, University of Washington, Seattle, WA 98195, USA \\ ${ }^{3}$ Department of Biological Structure, University of Washington, Box 357420 Seattle, WA 98195, USA \\ ${ }^{4}$ Seattle Children's, Seattle, WA 98105, USA \\ ${ }^{5}$ Department of Pathology and Laboratory Medicine, Medical University of South Carolina, Charleston, SC 29425, USA \\ ${ }^{6}$ Fred Hutchinson Cancer Research Center, Seattle, WA 98109, USA
}

Received: 29 July 2008; Accepted: 20 January 2009; Online publication: 25 February 2009

\begin{abstract}
The hair cells of the larval zebrafish lateral line provide a useful preparation in which to study hair cell death and to screen for genes and small molecules that modulate hair cell toxicity. We recently reported preliminary results from screening a small-molecule library for compounds that inhibit aminoglycoside-induced hair cell death. To potentially reduce the time required for development of drugs and drug combinations that can be clinically useful, we screened a library of 1,040 FDA-approved drugs and bioactive compounds (NINDS Custom Collection II). Seven compounds that protect against neomycin-induced hair cell death were identified. Four of the seven drugs inhibited aminoglycoside uptake, based on Texas-Red-conjugated gentamicin uptake. The activities of two of the remaining three drugs were evaluated using an in vitro adult mouse utricle preparation. One drug, 9-amino-1,2,3,4-tetrahydroacridine (tacrine) demonstrated conserved protective effects in the mouse utricle. These results demonstrate that the zebrafish lateral line can be used to screen successfully for drugs within a library of FDA-approved drugs and bioactives that inhibit hair cell death in the mammalian inner ear and identify tacrine as a promising protective drug for future studies.
\end{abstract}

Correspondence to: Henry C. Ou · Virginia Merrill Bloedel Hearing Research Center - University of Washington - Box 357923 Seattle, WA 98195, USA. Telephone: +1-206-5438360; fax: +1-206-2215685; email: henryou@u.washington.edu
Keywords: FDA library, zebrafish, hair cell, protection, ototoxicity, aminoglycoside

\section{INTRODUCTION}

Prevention of hair cell death is an important target for the prevention of hearing loss. Aminoglycoside ototoxicity due to hair cell death is clinically important and useful for studying hair cell loss (Forge and Li 2000; Forge and Schacht 2000; Schacht 1998). Many agents have been investigated as protective agents against aminoglycoside ototoxicity, but only a few, such as Dmethionine and aspirin (Campbell et al. 2007; Sha et al. 2006) have reached the point of clinical trials, with mixed results (Rizzi and Hirose 2007). Since clinical trials are costly, time-intensive, and highly regulated, it is helpful to focus efforts on protective drugs that have certain beneficial characteristics and thus have a relatively high probability of reaching clinical trials.

Previous studies have demonstrated the utility of the zebrafish for studying aminoglycoside and cisplatininduced hair cell death (Harris et al. 2003; Ou et al. 2007; Ton and Parng 2005; Williams and Holder 2000) as well as screening for protective (Owens et al. 2008) and ototoxic drugs (Chiu et al. 2008). This report describes the use of a library composed of FDA-approved drugs 
and bioactive compounds (NINDS Custom Collection II) to screen for candidate protective drugs. While this library has been used previously in other systems for the identification of promising compounds with neuroprotective capacity (Wang et al. 2005; Rothstein et al. 2005), this is the first reported use of this library to screen for drugs that protect against hair cell loss. This library has several advantages. The process of taking a new drug from preclinical validation to FDA approval is known to be long, arduous, and expensive. If an effective drug can be found among drugs that have been used in humans for other conditions, it may be possible to shorten this process considerably and reduce costs. In addition, a great deal of background information, including drug targets, is available for commercially approved drugs.

For drugs that protect against aminoglycosideinduced hair cell death to be candidates for clinical trials, we propose that a number of characteristics are desirable. (1) Drugs must be safe for administration in humans, preferably systemically rather than requiring local application, and with an acceptable toxicity profile; (2) they must cross the blood-brain barrier; (3) they must protect over a wide range of aminoglycoside doses; (4) they must not inhibit aminoglycoside uptake (i.e. inhibition of downstream cell death pathways); (5) they must not affect the bactericidal capacity of aminoglycosides; and (6) they must offer protection of mammalian hair cells.

This report describes the results of the screen of the NINDS Custom Collection library as well as further evaluation of the candidate drugs in the lateral line and mouse utricle with regards to the "ideal" drug characteristics described previously. Through these evaluations, tacrine (5-amino-1,2,3,4tetrahydroacridine) was identified as a particularly promising drug for further in vivo studies in mammals and potentially for clinical trials.

\section{MATERIALS AND METHODS}

All zebrafish procedures described have been approved by the University of Washington Animal Care and Use Committee. All mouse procedures described have been approved by the University of Washington Animal Care and Use Committee and the Medical University of South Carolina Animal Care and Use Committee.

\section{Animals}

Zebrafish. Zebrafish (Danio rerio) embryos of the $\mathrm{AB}$ wildtype strain were produced by paired matings of adult fish maintained at $28.5^{\circ} \mathrm{C}$ in the University of Washington zebrafish facility (Westerfield 2000). Embryos were maintained at a density of 50 embryos per $100 \mathrm{~mm}^{2}$ petri dish in embryo media $(1 \mathrm{mM} \mathrm{MgSO} 4,120 \mu \mathrm{M}$
$\mathrm{KH}_{2} \mathrm{PO} 4,74 \mu \mathrm{M} \mathrm{Na}{ }_{2} \mathrm{HPO}_{4}, 1 \mathrm{mM} \mathrm{CaCl}{ }_{2}, 500 \mu \mathrm{M} \mathrm{KCl}$, $15 \mu \mathrm{M} \mathrm{NaCl}$, and $500 \mu \mathrm{M} \mathrm{NaHCO} 3$ in $\mathrm{dH}_{2} \mathrm{O}$ ). At 4 days post-fertilization (dpf), larvae were fed live Paramecia.

Mice. Three- to six-week-old CBA/J male mice were obtained from Harlan Sprague Dawley, Inc. (Indianapolis, IN, USA) and maintained in the University of Washington Animal Care Facility or the Medical University of South Carolina Animal Care Facility.

\section{Labeling protocols}

For screening, live $5 \mathrm{dpf}$ zebrafish larvae were immersed in $2 \mu \mathrm{M}$ YO-PRO1 (Invitrogen, Carlsbad, CA, USA; Y3603) in embryo medium for 30 min then rinsed three times in embryo medium. YO-PRO1 used in this fashion selectively labels hair cell nuclei of the lateral line (Santos et al. 2006; Ou et al. 2007; Fig. 1A, B).

For quantification of hair cell loss, live $5 \mathrm{dpf}$ zebrafish larvae were exposed to $3 \mu \mathrm{M}$ fixable FM1-43FX (Invitrogen, Carlsbad, CA, USA; F-35355) for $30 \mathrm{~s}$ followed by three rinses in embryo medium. After euthanasia and fixation in $4 \%$ paraformaldehyde overnight $4^{\circ} \mathrm{C}$, labeled fish were then mounted in Fluoromount-G (SouthernBiotech, Birmingham, AL, USA; 0100-01) for fluorescence microscopy (Fig. 1C, D).

\section{Library}

The NINDS Custom Collection II (Microsource, Gaylordsville, CT, USA) library consists of 1,040 drugs and bioactive compounds, divided into 13 plates of 80 drugs each. All drugs are dissolved in DMSO at $10 \mathrm{mM}$ concentration and are unlabeled. We note that not all drugs in this library are FDA-approved, but all have known biological activity. In addition to the US FDAapproved compounds, many are approved for clinical use in other countries but have not received FDA approval.

\section{Screening protocol}

Five days post-fertilization zebrafish larvae were first labeled with YO-PRO1 as described above. One fish in $150 \mu \mathrm{L}$ of embryo medium was transferred into each well of a 96-well optical base plate (Nunc, Rochester, NY, USA) with 12 columns numbered 1 to 12 , and eight rows labeled A to $\mathrm{H}$. A multichannel pipettor was used to transfer $1.5 \mu \mathrm{L}$ of each drug into each well in columns 2 through 11 for a 1:100 dilution and a final concentration of $100 \mu \mathrm{M}$ with $1 \%$ DMSO. After pretreatment with the library drug for $1 \mathrm{~h}, 1.8 \mu \mathrm{L}$ of neomycin (Sigma, St. Louis, MO, USA) was added to each well for a final concentration of $200 \mu \mathrm{M}$ neomycin. Previous studies from our group have shown that this exposure condition leads to almost complete loss of hair cells in every neuromast (Harris et al. 2003; Murakami et al. 2003; Santos et al. 2006). After $1 \mathrm{~h}$ of neomycin exposure, the plate was 

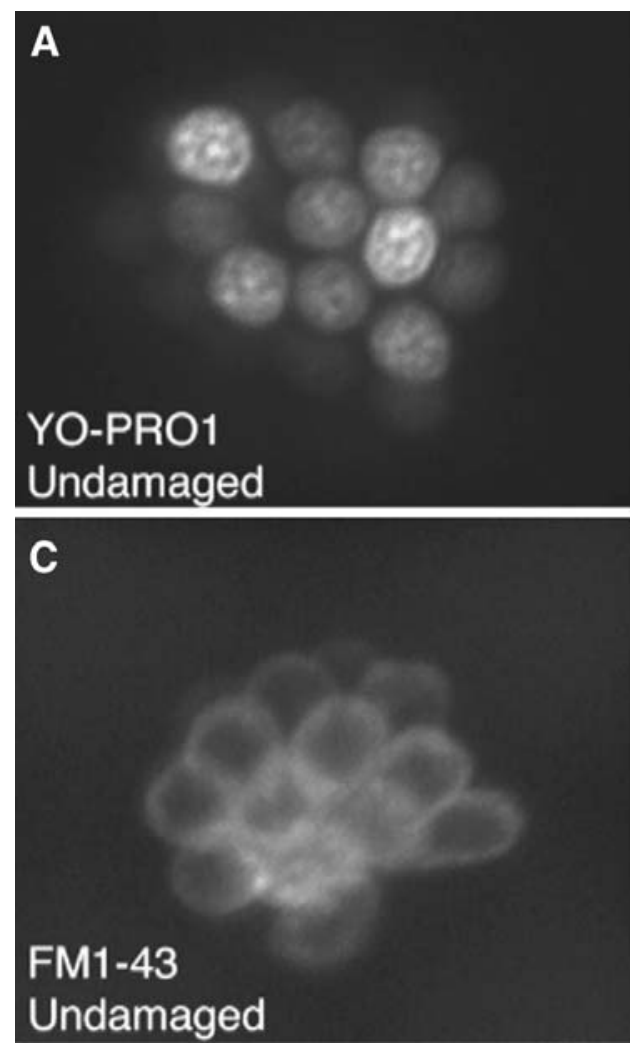

FIG. 1. Examples of normal and damaged fluorescently labeled hair cells of the zebrafish lateral line. YO-PRO1 selectively labels hair cell nuclei in normal (A) and neomycin-damaged (B) neuromasts. Hair cell protection can thus be easily assessed during screening. For quantitative

placed directly on the automated stage of an inverted epifluorescent Zeiss Axiovert 200M microscope and hair cell survival was rapidly assessed. Hair cell protection was graded on a scale of 0 (no protection) to 4 (complete protection) as has been described previously (Chiu et al. 2008). Approximately five to seven neuromasts were examined per fish at $\times 20$ to $\times 40$ magnifications. Wells in the first column of the 96-well plate contained a negative control (pretreatment with $1 \%$ DMSO followed by $200 \mu \mathrm{M}$ neomycin). Wells in the last column of the plate contained a positive control (pretreatment with $1 \%$ DMSO, no neomycin added). Screening of one 96-well plate typically required approximately $30 \mathrm{~min}$, meaning that the last well examined had approximately 30 additional minutes of exposure to neomycin.

\section{Dose-response testing}

Dose-response functions were performed to determine the effective dose range for each protective compound and to determine the efficacy of an optimal dose of drug against a range of neomycin concentrations.

Five days post-fertilization zebrafish larvae in groups ranging from 10-15 fish were prelabeled with the fixable dye FM1-43FX. To test optimal concentrations
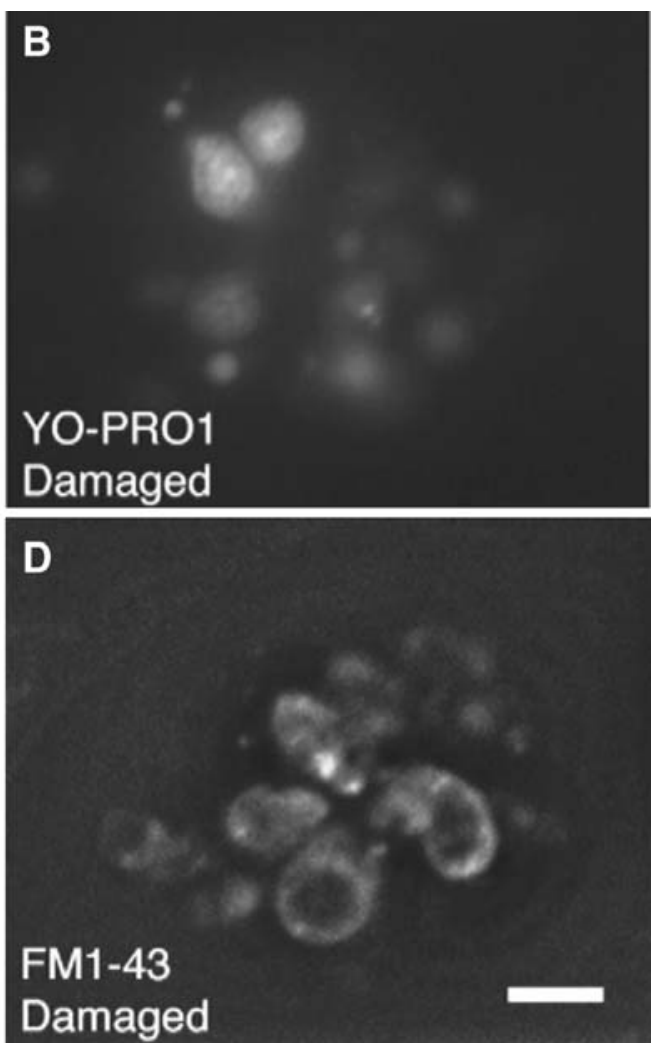

hair cell counts, FM1-43FX is used to count normal (C) and neomycindamaged (B) hair cells. In the undamaged neuromast (C) there are approximately 12 visible hair cells. In the damaged neuromast (D), there are two surviving hair cells. Scale bar in $\mathbf{D}=10 \mu \mathrm{M}$ and applies to all panels.

of drug, larvae were treated for $1 \mathrm{~h}$ with the candidate drug at $0,10,50,100$, and $200 \mu \mathrm{M}$ concentrations, followed by $200 \mu \mathrm{M}$ neomycin for $1 \mathrm{~h}$ with the candidate drug still present. To test the efficacy against a range of neomycin, larvae were treated with the optimal concentration (greatest protection with least toxicity) of protective drug for $1 \mathrm{~h}$ followed by treatment with 0 , 100,200 , and $400 \mu \mathrm{M}$ neomycin for $1 \mathrm{~h}$ with the candidate drug still present. Fish were then euthanized and immediately fixed overnight at $4^{\circ} \mathrm{C}$ in $4 \%$ paraformaldehyde, rinsed in phosphate-buffered solution (PBS), and mounted in Fluoromount-G on $25 \times 60 \mathrm{~mm}$ coverslips for imaging and counting. Hair cell counts were determined using fluorescence microscopy using a Zeiss Axioplan II microscope to count intact FM1-43FX labeled hair cells from the SO1, SO2, O1, and OC1 (Raible and Kruse 2000) neuromasts on one side of each fish. Typical hair cell counts for these four neuromasts are $8( \pm 2), 12( \pm 2), 10( \pm 3)$, and $7( \pm 3)$, respectively (Harris et al. 2003; Ou et al. 2007). Previous work has demonstrated that there is no significant differential sensitivity to aminoglycosides among neuromasts (Harris et al. 2003). Total hair cell counts were determined by adding the hair cell counts from the four neuromasts. Hair cell survival as a percentage of the 
control was calculated by dividing the total number of hair cells of each fish in the experimental group by the mean total number of hair cells in an undamaged control group (1\% DMSO pretreatment, no neomycin). Up to $2 \%$ DMSO does not protect against neomycininduced hair cell death in the zebrafish lateral line. In addition, 2\% DMSO does not independently cause hair cell death (unpublished observations).

\section{Twenty-four-hour survival counts}

Five days post-fertilization zebrafish were prelabeled with FM1-43, pretreated with the candidate drug for $1 \mathrm{~h}$, followed by $1 \mathrm{~h}$ of $200 \mu \mathrm{M}$ neomycin with the candidate drug still present. Both drugs were then washed out and zebrafish were allowed to recover for $24 \mathrm{~h}$. Zebrafish were then euthanized and fixed in $4 \%$ paraformaldehyde, mounted, and imaged. Hair cell survival in treated groups was compared to undamaged controls treated with only $1 \%$ DMSO for $1 \mathrm{~h}$ followed by $24 \mathrm{~h}$ of "recovery", as well as damaged controls treated with $1 \%$ DMSO followed by $1 \mathrm{~h}$ of $200 \mu \mathrm{M}$ neomycin and a 24-h recovery.

\section{Washout studies}

Five days post-fertilization zebrafish were prelabeled with FMI-43FX, pretreated with protective drug for $1 \mathrm{~h}$ then washed five times in embryo medium. Fish were then exposed to neomycin for $1 \mathrm{~h}$ and fixed and mounted. Hair cell survival in treated groups was compared to undamaged controls treated only with $1 \%$ DMSO, as well as damaged controls treated with $1 \%$ DMSO followed by an identical neomycin exposure.

\section{Aminoglycoside uptake}

After pretreatment with the candidate drug for $1 \mathrm{~h}$, 5 dpf zebrafish were exposed to $200 \mu \mathrm{M}$ Texas-Red conjugated gentamicin (TR-Gent; Steyger et al. 2003) while still in the presence of the candidate drug. Zebrafish were washed and then examined in vivo using fluorescence microscopy at 3 and 10 min after addition of the TR-Gent to assess uptake. Neuromasts were imaged with a Zeiss Axioplan II microscope using a Texas-Red filter set at $\times 40$ magnification. These experiments were repeated in triplicate for each drug. Control neuromasts exposed to unconjugated Texas Red alone did not demonstrate any uptake.

\section{Transduction channel integrity}

After pretreatment with the candidate drug for $1 \mathrm{~h}$, 5 dpf zebrafish were exposed to $4 \mu \mathrm{M}$ FM1-43 for $45 \mathrm{~s}$ and washed in embryo medium. Neuromasts were then imaged in vivo using fluorescence microscopy at 3 min after addition of FM1-43 to assess uptake. Neuromasts were imaged using a FITC filter set at $\times 40$ magnification. These experiments were repeated in triplicate for each drug. Only short duration FM1-43 exposures were tested because FM1-43 is known to be taken up by endocytotic pathways with longer exposures (Gale et al. 2001; Seiler and Nicolson 1999).

\section{Mouse utricle experiments}

Protective effects for cepharanthine and tacrine were examined in the mouse utricle. Mature mice (3 to 6 weeks of age) were sacrificed by overdose of nembutal. Utricles were then removed from the temporal bones using sterile technique and cultured in tissue culture plates (Cunningham et al. 2002) with a 2:1 mixture of basal medium Eagle and Earle's balanced salt solution, with 5\% fetal bovine serum (Invitrogen, Carlsbad, CA, USA). Utricles were cultured for $24 \mathrm{~h}$ with cepharanthine or tacrine at $0,1,10,50$, and $100 \mu \mathrm{M}$ concentrations to determine if there was any hair cell toxicity. Once the highest nontoxic dose was determined, utricles were treated with $4 \mathrm{~h}$ of pretreatment with the candidate drug, followed by $24 \mathrm{~h}$ with $2 \mathrm{mM}$ neomycin.

After treatment, otoconia were removed by a steady stream of phosphate-buffered solution. The utricles were then fixed overnight in $4 \%$ paraformaldehyde at $4^{\circ} \mathrm{C}$. After rinsing in PBS, utricles were placed in blocking solution ( $2 \%$ bovine serum albumin, $0.4 \%$ normal goat serum, $0.4 \%$ normal horse serum, $0.4 \%$ Triton X-100 in PBS) for $3 \mathrm{~h}$ at room temperature. Utricles were then double labeled with a monoclonal antibody against calmodulin (1:200; Sigma, St. Louis, MO, USA) and a polyclonal antibody against calbindin (1:250; Chemicon, Billerica, MA, USA) overnight at $4^{\circ} \mathrm{C}$. Calmodulin is present in the cytoplasm of all hair cells of the mouse utricle sensory epithelium, while calbindin labels only Type I hair cells that reside predominantly in the striola (Dechesne et al. 1988). After additional PBS washes, the utricles were then incubated with secondary antibody (Alexa 594 goat anti-rabbit IgG 1:500 and Alexa 488 horse anti-mouse IgG 1:500; Invitrogen, Carlsbad, CA, USA) for $2 \mathrm{~h}$ at room temperature. Utricles were then washed in PBS and mounted in Fluoromount-G (Southern Biotech, Birmingham, AL, USA).

Utricles were examined using a Zeiss Axioplan II fluorescence microscope with FITC (green) and Texas Red (red) filter sets at $\times 40$ magnification. Hair cell counts from four randomly selected $900 \mu \mathrm{m}^{2}$ areas from the striolar and extrastriolar regions were determined (Cunningham et al. 2002). Sample sizes were 11-15 utricles per condition.

Minimum inhibitory concentration and minimum bactericidal concentration testing

All candidate drugs were tested at $200 \mu \mathrm{M}$ concentration to determine whether they interfered with the 
known bactericidal activity of neomycin. Escherichia coli ATCG 25922 was used to inoculate the antibiotic dilutions. The MIC was tested in accordance with the National Clinical and Laboratory Standards Institute (Wikler 2006; Wikler 2007).

\section{Statistics}

All values were calculated and presented as the mean value $+1 \mathrm{SD}$ or the mean value +1 SEM. Statistical analyses were performed using one-way ANOVA, twoway ANOVA, and student $t$-test (VassarStats: faculty. Vassar.edu/lowry/VassarStats.html). Significant ANOVA main effects and interactions were followed by appropriate pairwise comparisons using Tukey's HSD test. Results were considered statistically significant if $p<0.05$.

\section{RESULTS}

\section{Initial screen}

The NINDS Custom Collection II (Microsource, Gaylordsville, CT, USA) was screened to identify compounds that protect against neomycin-induced hair cell damage. The library was developed to screen for drugs that have the potential to treat neurodegenerative diseases and has been used to study Huntington's disease (Wang et al.
2005) and amyotrophic lateral sclerosis (Rothstein et al. 2005). The 1,040 drugs represent a significant fraction of the total number of FDA-approved chemical entities. After a single pass through the 1,040 drug library, 20 drugs demonstrated high levels of protection (grade 3 to 4 ), for a "hit" rate of $\sim 2 \%$. Although the screen has a high rate of false positives, these were easily eliminated due to the ease of re-testing; all drugs found to demonstrate a high level of protection (grade 3 or 4 ) were retested in triplicate under identical experimental conditions. Protective effects in any of the three retests led to more thorough dose-response testing. Of these 20 drugs, seven demonstrated reproducible protection (Table 1). Of the seven drugs, carvedilol, 9-amino-1,2,3,4-tetrahydroacridine (tacrine), and phenoxybenzamine are FDAapproved. Amsacrine, drofenine, and cepharanthine have been used clinically in other countries, but are not yet FDA-approved. Hexamethyleneamiloride is a derivative of FDA-approved amiloride.

\section{Dose-response testing}

Dose-response relationships were determined for drugs found to be protective upon the confirmatory testing. We refer to this group as candidate drugs. Two sets of doseresponse relationships were determined for each candidate drug. In the first set of dose-response experiments,

\section{TABLE 1}

Candidate drugs identified by initial screen for protection and confirmed on retesting

\begin{tabular}{|c|c|c|}
\hline Candidate drug & Known activity & Crosses blood/brain barrier \\
\hline Amsacrine & $\begin{array}{l}\text { Topoisomerase } 2 \text { poison; used as } \\
\text { chemotherapeutic agent. Used } \\
\text { clinically in other countries, } \\
\text { not yet FDA-approved }\end{array}$ & Yes (Cornford et al. 1992) \\
\hline Carvedilol & $\begin{array}{l}\text { Beta-2 adrenergic blocker; used } \\
\text { for treatment of hypertension, } \\
\text { heartfailure. FDA-approved }\end{array}$ & Yes (Elsinga et al. 2004) \\
\hline Cepharanthine & $\begin{array}{l}\text { Plasma membrane stabilizer; used } \\
\text { for the treatment of nasal allergy, } \\
\text { snake venom hemolysis; possible } \\
\text { chemotherapeutic adjunct. Used } \\
\text { clinically in other countries, not yet } \\
\text { FDA-approved }\end{array}$ & Yes (Okamoto et al. 2001) \\
\hline Drofenine & $\begin{array}{l}\text { Acetylcholinesterase inhibitor; used as } \\
\text { antispasmodic. Used clinically in } \\
\text { other countries, not yet } \\
\text { FDA-approved }\end{array}$ & Yes (Kunysz et al. 1988) \\
\hline Hexamethyleneamiloride & $\begin{array}{l}\text { Diuretic, } \mathrm{Na} / \mathrm{H} \text { exchange inhibitor. } \\
\text { Derivative of amiloride, } \\
\text { FDA-approved diuretic }\end{array}$ & Yes (Ferimer et al. 1995) \\
\hline Phenoxybenzamine & $\begin{array}{l}\text { Alpha-1 adrenergic blocker; } \\
\text { used as Antihypertensive. } \\
\text { FDA-approved }\end{array}$ & Yes (Diop and Dausse 1986) \\
\hline 9-amino-1,2,3,4-tetrahydroacridine (tacrine) & $\begin{array}{l}\text { Anticholinergic; acetylcholinesterase } \\
\text { inhibitor, used for treatment } \\
\text { of Alzheimer's dementia. } \\
\text { FDA-approved }\end{array}$ & Yes (McNally et al. 1996) \\
\hline
\end{tabular}


$5 \mathrm{dpf}$ zebrafish larvae were pretreated for $1 \mathrm{~h}$ with each candidate drug at $0,10,50,100$, and $200 \mu \mathrm{M}$ concentrations and then treated with $200 \mu \mathrm{M}$ neomycin for $1 \mathrm{~h}$ with the candidate drug still present. Hair cell survival was calculated as a percentage of the hair cell counts from control animals treated identically, with pretreatment with $1 \%$ DMSO but no neomycin exposure. These experiments established dose-dependency and also assessed toxicity in the candidate drug's interaction with neomycin.

For each of the seven protective drugs, there was dose-dependent protection against neomycin-induced hair cell death in the zebrafish lateral line (Fig. 2A, Table 2). As noted in Table 2, hexamethyleneamiloride, cepharanthine, amsacrine, phenoxybenzamine, and tacrine demonstrated significant protection at $10 \mu \mathrm{M}$ and higher pretreatment concentrations. Carvedilol and drofenine demonstrated significant protection at all concentrations except the $200 \mu \mathrm{M}$ pretreatment concentration. At this concentration the compounds were toxic to fish, which may be indicative only of excessive dosing of the fish, rather than overall toxicity of these drugs to humans.

The lowest nontoxic pretreatment dose affording maximal protection against neomycin was determined for each drug and found to be as follows: $100 \mu \mathrm{M}$ cepharanthine, $50 \mu \mathrm{M}$ drofenine, $50 \mu \mathrm{M}$ tacrine, $50 \mu \mathrm{M}$ carvedilol, $50 \mu \mathrm{M}$ amsacrine, $50 \mu \mathrm{M}$ hexamethyleneamiloride, and $50 \mu \mathrm{M}$ phenoxybenzamine.

\section{Protection against variable doses of neomycin}

In the second set of dose-response experiments, the lowest nontoxic pretreatment dose affording maximal protection (greatest protection with least toxicity) for each drug was tested against different concentrations of neomycin. These experiments determined whether protection was maintained across a wide range of neomycin concentrations. In Figure 2B and Table 3, hair cell survival in fish pretreated with candidate drugs and then exposed to $0,100,200$, or $400 \mu \mathrm{M}$ neomycin (with candidate drug still present) are compared with fish that had no pretreatment with a candidate drug. Values represent the mean percentage hair cell survival compared to normal control animals without pretreatment and without exposure to neomycin. All seven drugs demonstrated significant protection over increasing doses of neomycin when compared to untreated controls (two-way ANOVA, $p<0.0001$, Table 3). These results suggest that the protective effects of all seven drugs are preserved at both higher and lower doses of neomycin.

\section{Twenty-four-hour survival}

To determine if hair cell loss was simply delayed by candidate drug treatment, we assessed hair cell survival after $24 \mathrm{~h}$. For all seven candidate drugs, hair cell survival

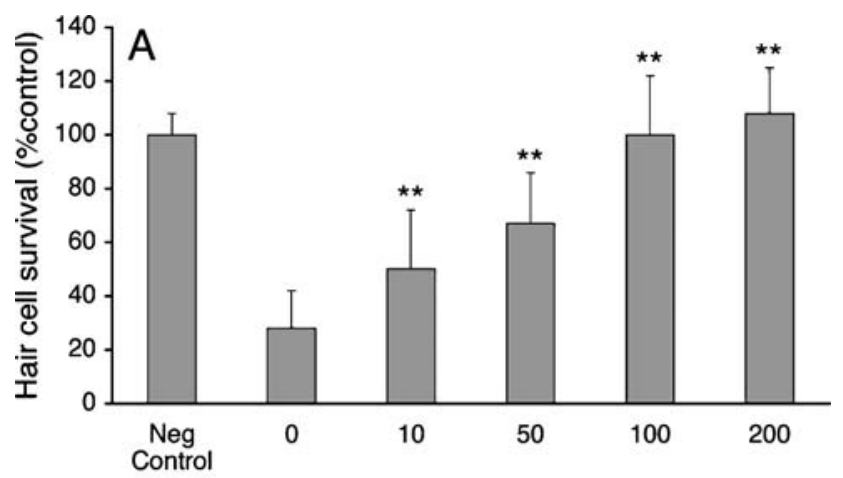

Cepharanthine concentration $(\mu \mathrm{M})$

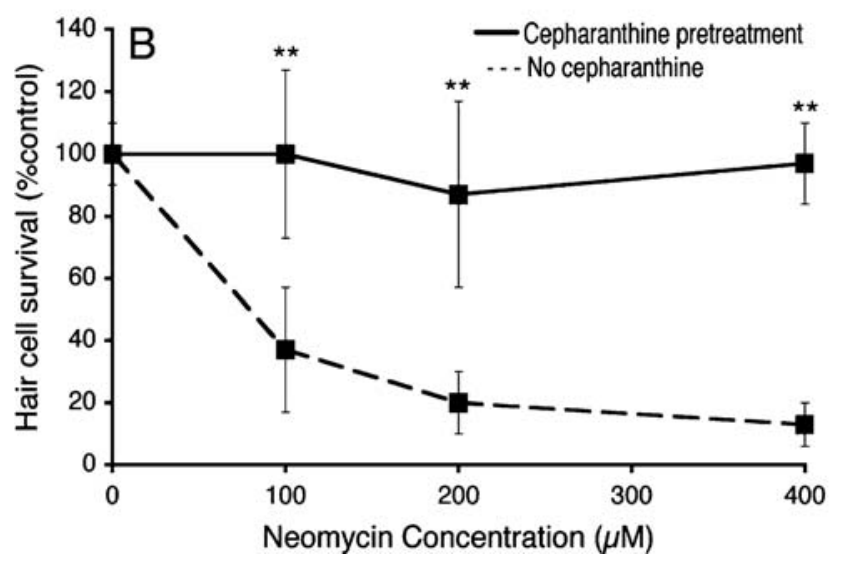

FIG. 2. Cepharanthine demonstrates significant protection against neomycin-induced hair cell loss. A Five days post-fertilization zebrafish pre-exposed to cepharanthine for $1 \mathrm{~h}$ and then treated with $200 \mu \mathrm{M}$ neomycin demonstrate significant dose-dependent protection by cepharanthine ${ }^{* *} p<0.01$, one-way ANOVA). B Five days post-fertilization zebrafish pre-exposed to $100 \mu \mathrm{M}$ cepharanthine and then treated with $0,100,200$, or $400 \mu \mathrm{M}$ neomycin. Solid line Zebrafish pretreated with cepharanthine prior to neomycin. Dotted line Zebrafish with no pretreatment prior to neomycin. Cepharanthine pretreatment led to significant protection against all doses of neomycin $(p<0.0001$, twoway ANOVA). For both graphs, data points represent mean hair cell survival of $10-15$ fish. Error bars $= \pm 1$ SD from the mean. Data for remaining six protective drugs are presented in Tables 2 and 3.

$24 \mathrm{~h}$ after treatment was significantly increased relative to unprotected, neomycin-treated controls $(p<0.001$, student $t$-test) and was not significantly different from survival $1 \mathrm{~h}$ after neomycin (Fig. 3). This suggests that hair cell death was not simply delayed by treatment with protective compounds and that hair cells alive after $1 \mathrm{~h}$ of neomycin remained alive thereafter.

\section{Washout studies}

To determine whether pretreatment protective effects persist after washout and removal of the protective drug prior to exposure to neomycin, larvae were pretreated with protective drug and then washed extensively before exposure to neomycin. When the protective drug was washed out prior to treatment with neomycin, cepharan- 
TABLE 2

Hair cell survival (percent of control) after pretreatment with increasing doses of candidate protective drugs followed by $200 \mu \mathrm{M}$ neomycin

\begin{tabular}{|c|c|c|c|c|c|}
\hline Candidate drug & $O \mu \mathrm{M}$ & $10 \mu \mathrm{M}$ & $50 \mu \mathrm{M}$ & $100 \mu \mathrm{M}$ & $200 \mu \mathrm{M}$ \\
\hline Amsacrine & $28 \pm 14$ & $50 \pm 11^{*}$ & $89 \pm 19 * *$ & $83 \pm 19 * *$ & $92 \pm 11^{* *}$ \\
\hline Carvedilol & $22 \pm 6$ & $72 \pm 8^{* *}$ & $92 \pm 28 * *$ & $97 \pm 17^{* *}$ & Dead \\
\hline Cepharanthine & $28 \pm 14$ & $50 \pm 22 * *$ & $67 \pm 19 * *$ & $100 \pm 22^{* *}$ & $108 \pm 17^{* *}$ \\
\hline Drofenine & $17 \pm 11$ & $39 \pm 14^{*}$ & $75 \pm 11^{* *}$ & $83 \pm 17^{* *}$ & Dead \\
\hline Hexamethyleneamiloride & $22 \pm 6$ & $39 \pm 17^{* *}$ & $86 \pm 19 * *$ & $89 \pm 22 * *$ & $100 \pm 17^{* *}$ \\
\hline Phenoxybenzamine & $17 \pm 11$ & $39 \pm 11 *$ & $72 \pm 14^{* *}$ & $86 \pm 19 * *$ & $89 \pm 19^{* *}$ \\
\hline Tacrine & $17 \pm 11$ & $31 \pm 11 * *$ & $61 \pm 14^{* *}$ & $64 \pm 17^{* *}$ & $83 \pm 19 * *$ \\
\hline
\end{tabular}

"Dead" indicates cases in which the pretreatment was toxic to the fish

${ }^{*} p<0.05 ;{ }^{* *} p<0.01$ (indicate statistically significant difference from control group treated with DMSO alone followed by neomycin, one-way ANOVA)

thine $(p<0.05$, student $t$-test $)$, phenoxybenzamine $(p<$ 0.0001 , student $t$-test $)$, drofenine $(p<0.0001$, student $t$-test), and carvedilol ( $p<0.0001$, student $t$-test) demonstrated significant hair cell protection relative to neomycin-treated control (Fig. 4). These results suggest that once these compounds are taken up by cells or bound to their targets, they are not effluxed or inactivated at a significant rate.

\section{Texas-Red conjugated gentamicin and FM1-43 uptake studies}

It is well known in both the zebrafish lateral line and the mammalian inner ear that drugs and genes that interfere with the integrity of the transduction channel reduce or eliminate aminoglycoside ototoxicity (Richardson et al. 1997; Gale et al. 2001; Seiler and Nicolson 1999; Zheng and Gao 1999). To determine if our candidate drugs reduce neuromast hair cell sensitivity to neomycin by interfering with transduction, we tested the integrity of transduction by examining FM1-43 uptake. To determine if candidate drugs block aminoglycoside uptake, we used TR-Gent (Steyger et al. 2003). Uptake of TR-Gent and
FM1-43 were judged as either normal, reduced, or blocked in neuromasts of at least three fish with each candidate drug at a concentration of $100 \mu \mathrm{M}$. Uptake of TR-Gent was completely blocked by carvedilol and phenoxybenzamine (Fig. 5), with no labeled hair cells at 3 and $10 \mathrm{~min}$. Hexamethyleneamiloride and amsacrine pretreatment demonstrated no uptake of TR-Gent at $3 \mathrm{~min}$, but full uptake at $10 \mathrm{~min}$. Cepharanthine, drofenine, and tacrine did not impact TR-Gent uptake with full uptake at 3 and $10 \mathrm{~min}$ (Table 4).

Uptake of FM1-43 after a short, 45 s, exposure was blocked only by phenoxybenzamine. All other drugs tested demonstrated no impact on the rapid uptake of FM1-43 (Table 4). These results demonstrate that the screen identified some drugs that protect against aminoglycoside-induced hair cell death at the level of drug uptake and others that may affect intracellular pathways.

\section{Inhibition of bactericidal activity}

To be therapeutically effective, candidate drugs should not interfere with the bactericidal activity of aminoglycosides. None of the seven drugs significantly

TABLE 3

Hair cell survival (percent of control) in the zebrafish lateral line after pretreatment with protective drug followed by variable doses of neomycin

\begin{tabular}{|c|c|c|c|c|}
\hline \multirow[b]{2}{*}{ Candidate drug } & \multicolumn{4}{|c|}{ Neomycin dose given after pretreatment } \\
\hline & 0 & 100 & 200 & 400 \\
\hline No pretreatment & $100 \pm 10$ & $37 \pm 20$ & $20 \pm 10$ & $13 \pm 7$ \\
\hline Amsacrine & $100 \pm 15$ & $83 \pm 13 *$ & $93 \pm 10^{*}$ & $77 \pm 17^{*}$ \\
\hline Carvedilol & $100 \pm 10$ & $110 \pm 17^{*}$ & $90 \pm 13^{*}$ & $80 \pm 20 *$ \\
\hline Cepharanthine & $100 \pm 11$ & $100 \pm 27^{*}$ & $87 \pm 30^{*}$ & $97 \pm 13^{*}$ \\
\hline Drofenine & $100 \pm 13$ & $67 \pm 20^{*}$ & $70 \pm 13^{*}$ & $60 \pm 13^{*}$ \\
\hline Hexamethyleneamiloride & $100 \pm 11$ & $90 \pm 30^{*}$ & $80 \pm 20 *$ & $73 \pm 20 *$ \\
\hline Phenoxybenzamine & $100 \pm 10$ & $63 \pm 7^{*}$ & $67 \pm 10^{*}$ & $60 \pm 13^{*}$ \\
\hline Tacrine & $100 \pm 12$ & $80 \pm 20 *$ & $87 \pm 13^{*}$ & $67 \pm 13^{*}$ \\
\hline
\end{tabular}

Zebrafish were pretreated with highest nontoxic dose of protective drug (100 $\mu \mathrm{M}$ cepharanthine, $50 \mu \mathrm{M}$ drofenine, $50 \mu \mathrm{M}$ tacrine, $50 \mu \mathrm{M}$ carvedilol, $50 \mu \mathrm{M}$ amsacrine, $50 \mu \mathrm{M}$ hexamethyleneamiloride, and $50 \mu \mathrm{M}$ phenoxybenzamine)

${ }^{*} p<0.01$ denotes statistically significant difference compared to control, two-way ANOVA 


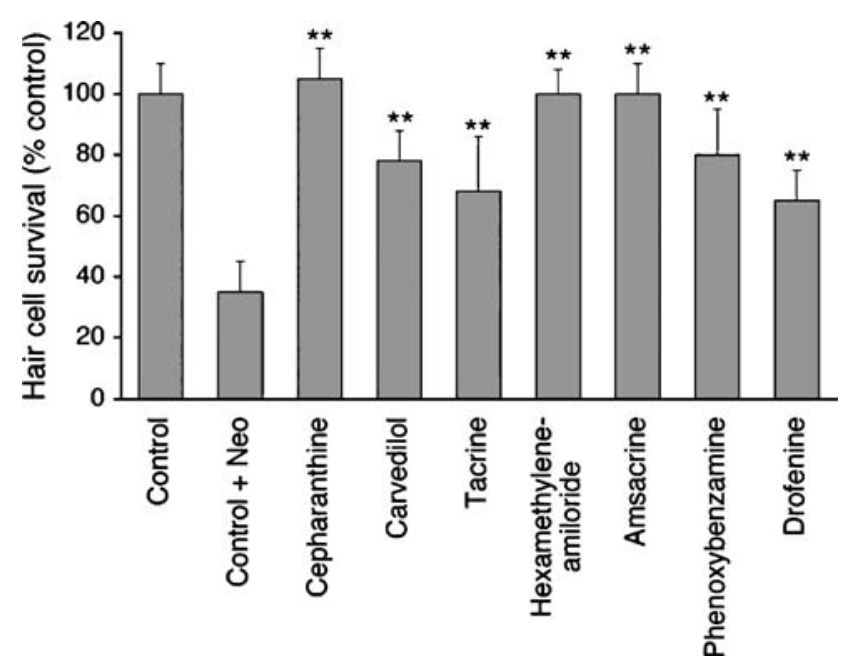

FIG. 3. Twenty-four hour hair cell survival after neomycin. Fluorescently labeled $5 \mathrm{dpf}$ zebrafish were pretreated with each protective drug for $1 \mathrm{~h}$, followed by treatment with $200 \mu \mathrm{M}$ neomycin for $1 \mathrm{~h}$. Zebrafish then recovered for $24 \mathrm{~h}$, and then were fixed for hair cell counts. All seven drugs demonstrated significant protection $24 \mathrm{~h}$ after the neomycin exposure relative to control + neomycin $\left(^{* *} p<0.01\right.$, student $t$-test). Bars represent mean hair cell survival of 10-15 fish. Error bars $= \pm 1$ SD from the mean.

increased the minimum inhibitory concentration (MIC) or the minimum bactericidal concentration (MBC) of neomycin. All seven drugs demonstrated no greater than a twofold change in the minimum inhibitory concentration $(2.0 \mu \mathrm{g} / \mathrm{ml})$ and minimum bactericidal concentration $(2.0 \mu \mathrm{g} / \mathrm{ml})$ of neomycin. Up to a twofold increase is considered within the normal variation of the test (Wikler 2006; Wikler 2007). This indicates that co-administration of these protective drugs would not be expected to interfere with the desired antibacterial properties of neomycin.

\section{Mouse utricle studies}

To begin determining whether the intracellular protective effects revealed by our screening procedures are conserved in the mammalian inner ear, cepharanthine and tacrine were tested for their ability to protect mature mammalian inner ear hair cells from neomycin-induced hair cell death. Explants of mature mouse utricles were pretreated with these drugs with or without subsequent neomycin exposure.

Cepharanthine was found to be toxic to mouse utricle hair cells at all of the tested concentrations $(1,10,50$, and $100 \mu \mathrm{M})$. While it is possible that cepharanthine may have protective effects below $1 \mu \mathrm{M}$, no protective trials for cepharanthine against neomycin were performed on mouse utricles. In contrast, tacrine demonstrated protective effects against neomycin in the mouse utricle. When pretreated with $10 \mu \mathrm{M}$ tacrine, both striolar and extrastriolar hair cells were protected against $2 \mathrm{mM}$ neomycin-induced cell death $(p<0.01$, one-way ANOVA; Fig. 6). These results demonstrate that the zebrafish lateral line can be used to successfully identify drugs that inhibit hair cell death in the mammalian inner ear.

\section{DISCUSSION}

Previously, our laboratory used the zebrafish lateral line to screen a small molecule library for protective agents (Owens et al. 2008). That study identified two chemicals (PROTO1 and 2) with protective effects against hair cell death. While PROTO1 and 2 are candidates for drug development, FDA approval of new drugs requires an average of 12 years and the odds of a new drug becoming approved are approximately one out of 5,000 (Wierenga and Eaton 1993). Applying the same screen to the NINDS Custom Collection is potentially more efficient. Compounds in this library have proven drug-like properties such as solubility and cell permeability in contrast to the less well-characterized small molecule libraries. Use of this library bypasses certain aspects of drug development and moves more rapidly towards identifying an "ideal" candidate protective drug as defined above. By evaluating the seven candidate protective drugs identified in the screen with regards to

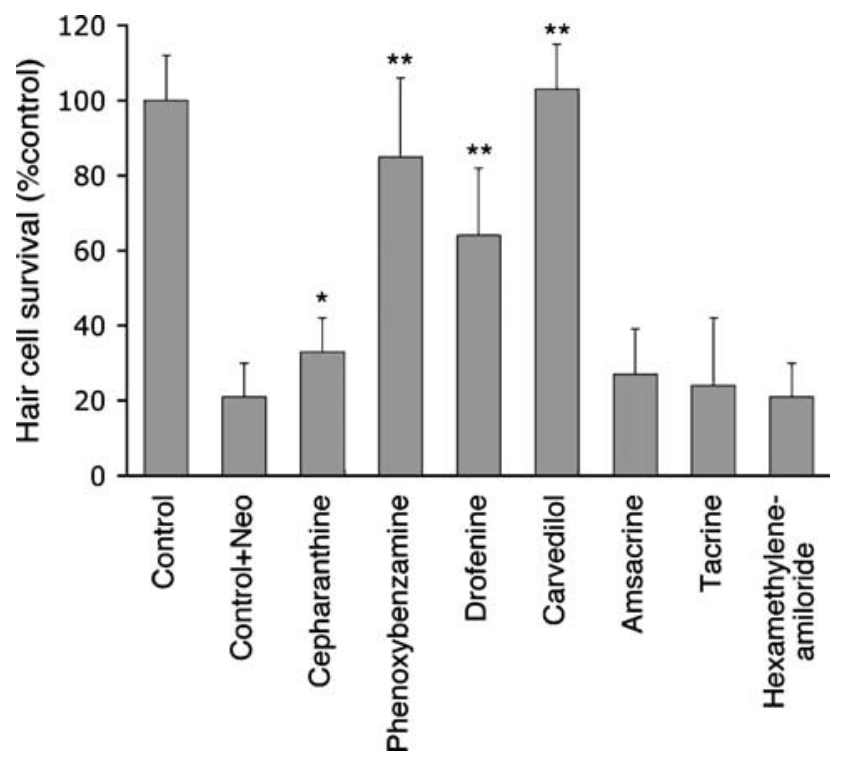

FIG. 4. Protection after pre-neomycin washout. Fluorescently labeled $5 \mathrm{dpf}$ zebrafish were pretreated with each protective drug for $1 \mathrm{~h}$. The protective drug was then washed out with multiple rinses in embryo media. Fish were then treated with $200 \mu \mathrm{M}$ neomycin for $1 \mathrm{~h}$ and then fixed for hair cell counts. Only phenoxybenzamine, drofenine, and carvedilol demonstrated significant protection relative to control + neomycin $\left({ }^{*} p<0.05 ;{ }^{* *} p<0.01\right.$, student $t$-test). Bars represent mean hair cell survival of $10-15$ fish. Error bars $= \pm$ SD from the mean. 


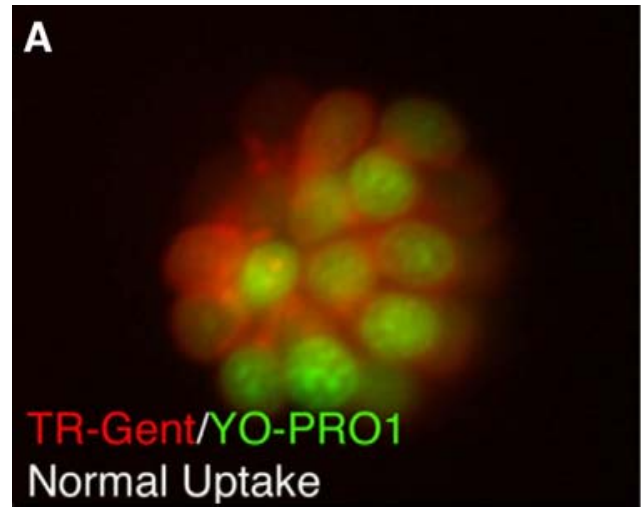

FIG. 5. Examples of normal and blocked uptake of Texas-Red conjugated gentamicin (TR-Gent) in the zebrafish lateral line. Hair cells are labeled with YO-PRO1 (green) to label hair cell nuclei, and TR-Gent (red). A Normal uptake of TR-Gent demonstrates multiple double-labeled hair cells. B Uptake of TR-Gent is

these six characteristics, tacrine was identified as a protective drug worthy of future study.

\section{Safety of administration}

In searching for a protective compound for the inner ear, ease of administration is an important factor. Some compounds are not practical for systemic administration or may only be effective when delivered directly to the inner ear (e.g. JNK inhibitors and caspase inhibitors; Wang et al. 2003; Zine and van de Water 2004). Systemic administration avoids the need for invasive intracochlear or transtympanic drug applications. All seven of the candidate drugs have been used systemically in humans, although only carvedilol, tacrine, and phenoxybenzamine are currently FDA-approved. The others have been used in experimental protocols or countries outside of the USA.

The clinical uses for these drugs provide insight into their potential as protective drugs. Amsacrine is a topoisomerase II poison and is generally cytotoxic (Rowe et al. 1986) and thus impractical for systemic use as an inner ear protectant. Hexamethyleneamiloride is a $\mathrm{Na} / \mathrm{H}$-exchange blocker used as a diuretic (Davies and Solioz 1992). Phenoxybenzamine (alpha-

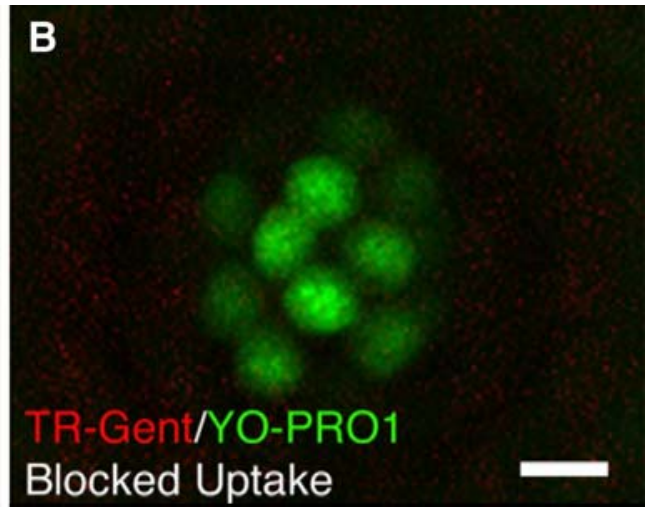

blocked by pretreatment with the candidate protective drug, phenoxybenzamine. No double-labeled hair cells are seen. Similar findings were seen with carvedilol, hexamethyleneamiloride, and amsacrine. Scale bar in $\mathrm{B}=10 \mu \mathrm{M}$ and applies to both panels.

adrenergic blocker) and carvedilol (beta-adrenergic blocker) are both used to treat hypertension (Osnes et al. 2000). Cepharanthine has membrane-stabilizing activity and is used for treatment of nasal allergy and snake venom hemolysis (Furusawa and Wu 2007; Kohno et al. 1987). Drofenine and tacrine are acetylcholinesterase inhibitors used for muscle relaxation and Alzheimer's dementia, respectively (Bodur et al. 2001; Drukarch et al. 1987).

\section{Blood-brain barrier penetration}

All seven drugs cross the blood-brain barrier (Table 1). The kinetics of inner ear penetration for these drugs is unknown. It is also unknown whether crossing the blood-brain barrier is critical for a potential inner ear protectant, however this would seem to improve the odds of diffusion into the perilymph and possibly endolymph.

\section{Protection against a wide-range of aminoglycoside doses}

The ideal protective drug would protect hair cells over a wide range of aminoglycoside dosages. The efficiency of testing in the zebrafish permits thorough investigation

TABLE 4

\begin{tabular}{lrr}
\hline & \multicolumn{2}{c}{ Uptake of Texas Red-conjugated gentamicin and FM1-43 after pretreatment with candidate drugs } \\
\hline Drug & Texas Red-conjugated gentamicin uptake & Rapid FM1-43 uptake \\
\hline Amsacrine & Reduced & Normal \\
Carvedilol & Blocked & Normal \\
Cepharanthine & Normal & Normal \\
Drofenine & Normal & Normal \\
Hexamethyleneamiloride & Reduced & Normal \\
Phenoxybenzamine & Blocked & Blocked \\
Tacrine & Normal & Normal \\
\hline
\end{tabular}



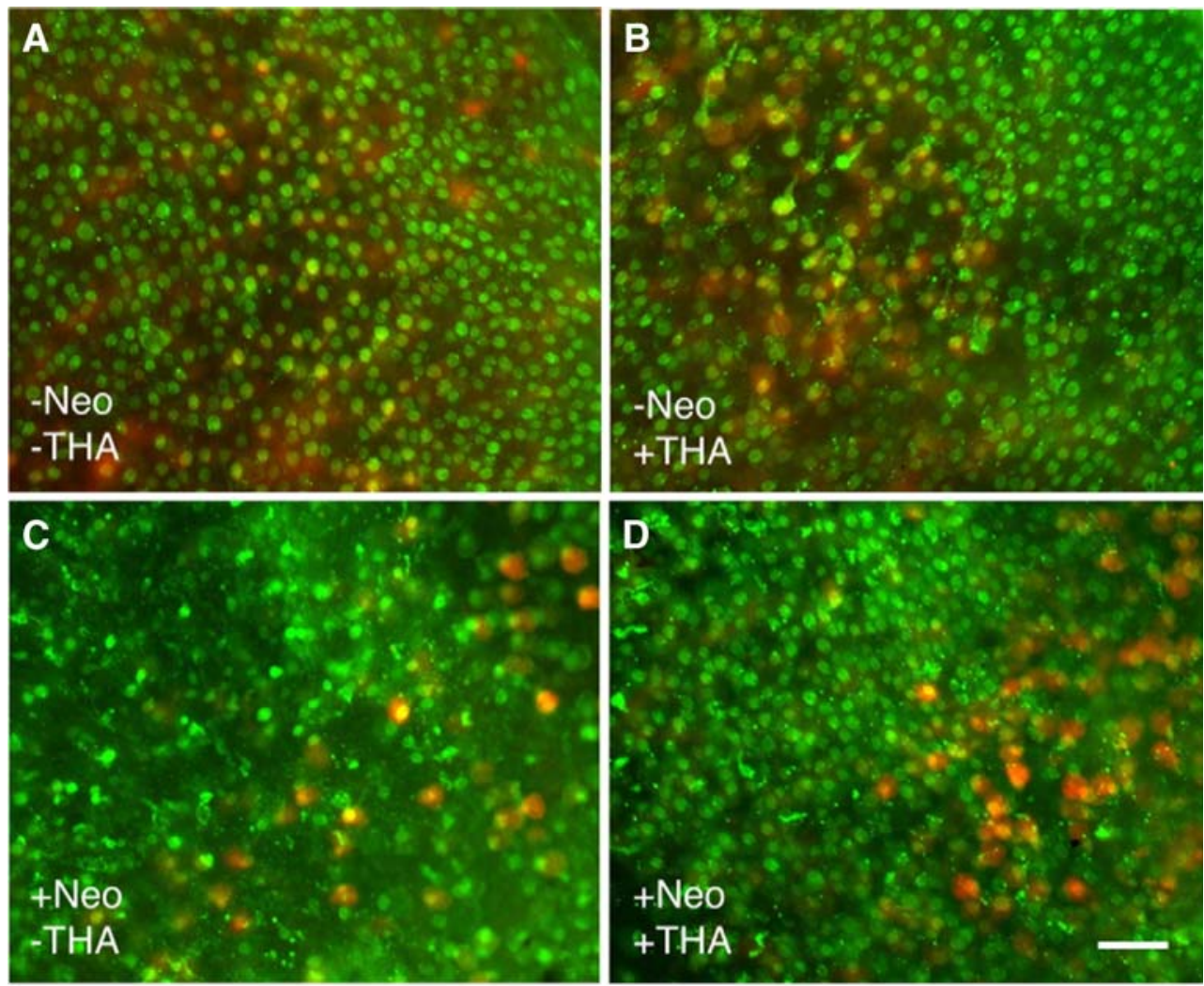

\section{E}

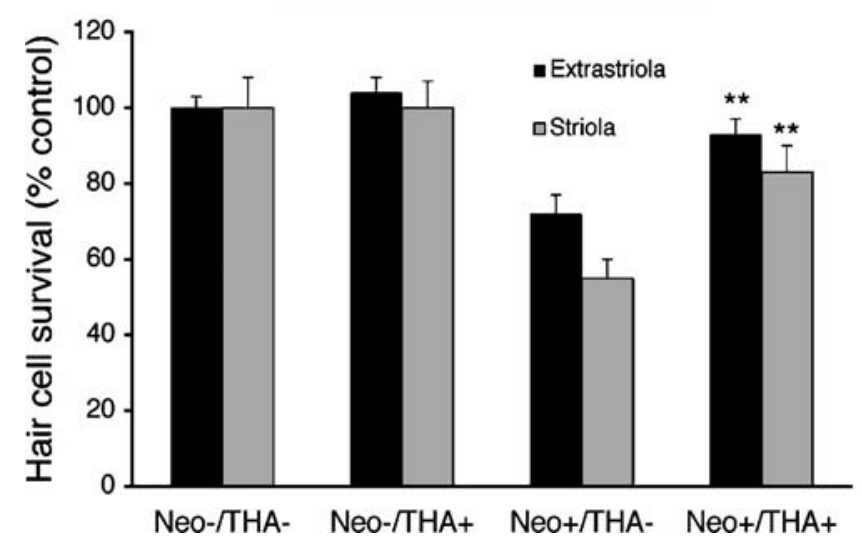

FIG. 6. Tacrine (THA) protects against neomycin-induced hair cell death in mouse utricle explants. Utricles were pretreated with $10 \mu \mathrm{M}$ tacrine for $4 \mathrm{~h}$, followed by $2 \mathrm{mM}$ neomycin and THA for $24 \mathrm{~h}$. Utricles were then fixed and labeled with antibodies against calmodulin (green) and calbindin (red). A Control utricle not treated with neomycin or THA. B Utricle pretreated with THA without neomycin exposure. Ten micromolar THA did not cause any hair cell loss. C Utricle without THA pretreatment, but treated with $2 \mathrm{mM}$ neomycin demonstrates marked striolar and extrastriolar hair cell loss with a decrease in calmodulin and calbindin labeling. There is also an increase in cellular debris from dying hair cells. D Utricle pretreated with THA then treated with $2 \mathrm{mM}$ neomycin demonstrates protection against hair cell loss. Scale bar in $\mathrm{D}=20 \mu \mathrm{M}$ and applies to all panels. E Hair cell survival is significantly increased ( $p<0.01$, one-way ANOVA) in both extrastriolar and striolar hair cells when utricles were pretreated with THA prior to neomycin $(\mathrm{NeO}+/ \mathrm{THA}+)$ compared to control utricles without THA pretreatment (Neo+/THA-). Bars represent the mean hair cell survival $(\%$ control $)+1$ SEM ( $n=11-15$ utricles per group). of hair cell protection. We tested a range of concentrations of each protectant and tested each protectant against a range of neomycin concentrations. Testing a range of protectant concentrations is important because some protectants have been found to be toxic at higher concentrations. In addition, protective compounds effective against a narrow range of aminoglycoside concentrations may have limited clinical utility (Sugahara et al. 2006). In this study, all candidate drugs were protective against a wide range of neomycin doses in the zebrafish lateral line, preserving a range of $60 \%$ to $100 \%$ of the hair cells. 
We hypothesize that the variability in the magnitude of protective effects is due to differential effects on the multiple death pathways activated by aminoglycoside exposure. The mechanisms underlying aminoglycosideinduced hair cell death remain controversial, with both caspase-dependent and caspase-independent pathways implicated (Cunningham et al. 2002; Matsui et al. 2003; Jiang et al. 2006). Inhibition of one death pathway likely still allows (or possibly even facilitates) death through alternate pathways (Lin et al. 1999; Yu et al. 2004). Although some of the drugs identified in this study achieved complete protection in the lateral line, ultimately, a protective "cocktail" composed of multiple drugs may be a more effective regimen for prevention of hair cell death.

\section{Effects on aminoglycoside uptake}

Three candidate drugs, drofenine, tacrine, and cepharanthine, did not affect TR-Gent uptake. Ideally, a protective drug identified in this neomycin-driven screen would inhibit intracellular death pathways triggered by an aminoglycoside rather than inhibiting aminoglycoside uptake. This drug would have more potential applications against a wider variety of causes of hair cell death.

While our tendency is to focus on drugs that affect cell death pathways, it is important to recognize that drugs that blocked aminoglycoside uptake may also have clinical relevance. These drugs could be administered systemically or locally to block ototoxicity of the aminoglycoside without affecting its bactericidal capacity or perturbing intracellular pathways. Hexamethyleneamiloride, amsacrine, carvedilol, and phenoxybenzamine blocked the uptake of TR-Gent. Hexamethyleneamiloride, as an amiloride derivative, is likely to block the mechanotransduction channel. The mechanisms of blockade by carvedilol, amsacrine, and phenoxybenzamine are unknown. Of these drugs, only phenoxybenzamine also affected FM1-43 uptake. This differential blockade between FM1-43 and TR-Gent suggests either different mechanisms of uptake, differing sensitivity to channel blockade, or different sensitivities of our detection methods.

\section{Effects on bactericidal activity of aminoglycoside}

None of the seven drugs affected the bactericidal activity of neomycin. This has obvious importance for potential use as an aminoglycoside-specific protective drug.

\section{Protection in mammalian tissue}

Hair cell protection in the zebrafish lateral line does not assure protection in mammalian hair cells, and thus testing was performed in the mouse utricle.
Due to the more time-consuming nature of mammalian testing, only two of the seven drugs were tested in the utricle, cepharanthine and tacrine. These two drugs were chosen because they were effective protective drugs that did not inhibit aminoglycoside uptake. Tacrine demonstrated significant protection against neomycin-induced hair cell death in mouse utricle explants. In contrast, cepharanthine was found to cause hair cell death at moderate concentrations, and thus further experiments examining its protective effects were not conducted. Tacrine is particularly interesting because its derivative, bis(7)-tetrahydroacridine, stabilizes the mitochondrial membrane potential and has been used experimentally as a neuroprotectant (Fu et al. 2006; Fu et al. 2007).

The lack of hair cell protection by cepharanthine in the mouse utricle demonstrates the importance of confirming findings from zebrafish in mammalian systems. However, there are critical differences between the exposure conditions of lateral line hair cells and freefloating utricle hair cells. Free-floating utricles have been removed from the organism, and thus any neural input has been removed. Secondly, lateral line hair cells are exposed to drugs predominantly at their apices, while free-floating utricles are bathed circumferentially. Lastly, one can hypothesize that hair cells in vitro may be more fragile and susceptible to cell death than hair cells in vivo.

\section{Conclusions}

This study represents the first screen of a library of compounds with known bioactivity for drugs that protect against aminoglycoside-induced hair cell death. Further evaluation of the screen identified tacrine as a particularly promising drug. Tacrine demonstrates protection against a wide range of neomycin doses, can be administered systemically, crosses the blood-brain barrier, does not inhibit aminoglycoside uptake, does not interfere with the bactericidal activity of neomycin, and is effective in mammalian utricle explants. Tacrine also has known targets as an acetylcholinesterase inhibitor and stabilizer of mitochondrial membrane potential. Tacrine is thus an excellent candidate for further investigation through in vivo testing, evaluation of its mechanism of action (cholinergic versus off-target effects), and evaluation of its potential as a protective drug against other challenges such as cisplatin, noise, and even aging.

\section{Caveats}

The results of this screen are not meant to suggest that none of the other compounds in the library have protective effects. In particular, many antioxidants are known to protect against hair cell death and were not detected in the screen. Varying the screening conditions would likely identify additional protective drugs and is worthy of future study. For example, protection against 
hair cell death in the zebrafish lateral line has been shown to require a 24-h exposure to antioxidants such as D-methionine and glutathione (Ton and Parng 2005).

Some protection may be due to global effects on the organism (e.g. increasing renal clearance of neomycin) rather than specific effects on the hair cell. We think this is unlikely since aminoglycosides appear to enter lateral line hair cells directly from the medium rather than depending on circulation or tissue accumulation.

It is important to note that tacrine has known hepatotoxicity that has hindered its use for the treatment of Alzheimer's dementia. In a multicenter clinical trial of tacrine, $49 \%$ of patients demonstrated an elevation of liver transaminases at a mean of 50 days after initiation of therapy (Watkins et al. 1994). Most of these patients were asymptomatic and had a return to normal liver function levels after withdrawal of the drug. Of the patients that had tacrine therapy resumed, $88 \%$ were able to resume long-term use of the drug. A number of possible mechanisms for this hepatotoxicity have been implicated, including poisoning of topoisomerases (Mansouri et al. 2003). It is likely that this toxicity occurs via a separate mechanism from its protective effect seen in hair cells. It may be possible to decrease the tacrine dose to minimize toxicity while maintaining its protective effects in hair cells. In addition, it is likely that for hair cell protection protocols, tacrine would be administered for days to weeks, rather than the months to years required for treatment of Alzheimer's dementia. Tacrine hybrid compounds are currently being developed (Fang et al. 2008) with potent activity but reduced hepatotoxicity. It remains to be seen whether these modifications would also reduce the protective effects seen in hair cells.

Limited mammalian data are presented due to the time-consuming nature of mammalian experiments. Additional studies are imperative for further progress. Lateral line hair cells have important differences from inner ear hair cells. There is no separation of fluid spaces in the lateral line so the apical surfaces of hair cells extend into the surrounding water. In addition, since there is no stria vascularis, drugs that act through strial mechanisms will not be identified. We view the screen as an efficient method for rapidly identifying candidate drugs that must then be confirmed in the mammalian inner ear.

\section{ACKNOWLEDGEMENTS}

This research was supported by grants from NIH/NIDCD: DC0018, DC04661, DC05987, DC07613, the National Organization for Hearing Research, NIH/NCRR: C06RR015455, C06RR14516, and the University of Washington Royalty Research Fund. The authors would like to thank Glen MacDonald, Mae Del Puerto, Brock Roberts, and Sue Swanzy for their technical expertise.

\section{REFERENCES}

Bodur E, Cokugras AN. Tezcan EF. Inhibition effects of benactyzine and drofenine on human serum butyrylcholinesterase. Arch. Biochem. Biophys. 386:25-29, 2001.

Campbell KC, Meech RP, Klemens JJ, Gerberi MT, Dyrstad SS, Larsen DL, Mitchell DL, El-Azizi M, Verhulst SJ, Hughes LF. Prevention of noise- and drug-induced hearing loss with D-methionine. Hear. Res. 226:92-103, 2007.

Chiu LL, Cunningham LL, Raible DW, Rubel EW, Ou HC. Using the zebrafish lateral line to screen for ototoxicity. J. Assoc. Res. Otolaryngol. 9:178-190, 2008.

Cornford EM, Young D, PAXTon JW. Comparison of the blood-brain barrier and liver penetration of acridine antitumor drugs. Cancer. Chemother. Pharmacol. 29(6):439-444, 1992.

Cunningham LL, Cheng AG, Rubel EW. Caspase activation in hair cells of the mouse utricle exposed to neomycin. J. Neurosci. 22:8532-8540, 2002.

Davies K, Solioz M. Assessment of uncoupling by amiloride analogs. Biochemistry. 31:8055-8058, 1992.

Dechesne CJ, Thomasset M, Brehier A, Sans A. Calbindin (CaBP $28 \mathrm{kDa}$ ) localization in the peripheral vestibular system of various vertebrates. Hear. Res.L. 33:273-278, 1988.

Diop L, Dausse JP. Specific binding of 3H-nicergoline in rat brain: comparison with the selective alpha 1-antagonist $3 \mathrm{H}$-prazosin. J. Pharmacol. 17(1):65-74, 1986.

Drukarch B, Kits KS, Van der Meer EG, Lodder JC, Stoof JC. 9-Amino1,2,3,4-tetrahydroacridine (THA), an alleged drug for the treatment of Alzheimer's disease, inhibits acetylcholinesterase activity and slow outward K+ current. Eur. J. Pharmacol. 141:153-157, 1987.

Elsinga PH, Hendrikse NH, Bart J, VaAlburg W, van WaArde A. PET Studies on P-glycoprotein function in the blood-brain barrier: how it affects uptake and binding of drugs within the CNS. Curr. Pharm. Des. 10(13):1493-1503, 2004.

Fang L, Appenroth D, Decker M, Kiehntopf M, Lupp A, Peng S, Fleck C, Zhang Y, Lehmann J. NO-donating tacrine hybrid compounds improve scopolamine-induced cognition impairment and show less hepatotoxicity. J. Med. Chem. 51(24):7666-7669, 2008.

Ferimer HN, Kutina KL, LaManna JC. Methyl isobutyle amiloride delays normalization of brain intracellular $\mathrm{pH}$ after cardiac arrest in rats. Crit. Care. Med. 23(6):1106-1111, 1995.

Forge A, Li L. Apoptotic death of hair cells in mammalian vestibular sensory epithelia. Hear. Res. 139:97-115, 2000.

Forge A, Schacht J. Aminoglycoside antibiotics. Audiol. Neurootol. 5:3-22, 2000.

Fu H, Li W, Lao Y, Luo J, Lee NT, Kan KK, Tsang HW, Tsim KW, Pang Y, Li Z, Chang DC, Li M, Han Y. Bis(7)-tacrine attenuates beta amyloid-induced neuronal apoptosis by regulating L-type calcium channels. J. Neurochem. 98:1400-1410, 2006.

Fu H, Li W, Liu Y, Lao Y, Liu W, Chen C, Yu H, Lee NT, Chang DC, Li P, PAnG Y, Tsim KW, Li M, Han Y. Mitochondrial proteomic analysis and characterization of the intracellular mechanisms of bis(7)-tacrine in protecting against glutamate-induced excitotoxicity in primary cultured neurons. J. Proteome. Res. 6:2435-2446, 2007.

Furusawa S, Wu J. The effects of biscoclaurine alkaloid cepharanthine on mammalian cells: implications for cancer, shock, and inflammatory diseases. Life. Sci. 80:1073-1079, 2007.

Gale JE, Marcotti W, Kennedy HJ, Kros CJ, Richardson GP. FM143 dye behaves as a permeant blocker of the hair-cell mechanotransducer channel. J. Neurosci. 21:7013-7025, 2001.

Harris JA, Cheng AG, Cunningham LL, MacDonald G, Raible DW, Rubel EW. Neomycin-induced hair cell death and rapid regeneration in the lateral line of zebrafish (Danio rerio). J. Assoc. Res. Otolaryngol. 4:219-234, 2003.

Jiang H, Sha SH, Forge A, Schacht J. Caspase-independent pathways of hair cell death induced by kanamycin in vivo. Cell. Death. Differ. 13:20-30, 2006. 
Kohno H, Inoue H, Seyama Y, Yamashita S, Akasu M. [Mode of the anti-allergic action of cepharanthine on an experimental model of allergic rhinitis]. Nippon. Yakurigaku. Zasshi. 90:205-211, 1987.

Kunysz EL, Michel AD, Whiting RL. Functional and direct binding studies using subtype selective muscarinic receptor antagonists. Br. J. Pharmacol. 93:491-500, 1988.

Lin Y, Devin A, Rodriguez Y, Liu ZG. Cleavage of the death domain kinase RIP by caspase-8 prompts TNF-induced apoptosis. Genes. Dev. 13:2514-2526, 1999.

Mansouri A, Haouzi D, Descatoire V, Demeilliers C, Sutton A, Vadrot N, Fromenty B, Feldmann G, Pessayre D, Berson A. Tacrine inhibits topoisomerases and DNA synthesis to cause mitochondrial DNA depletion and apoptosis in mouse liver. Hepatology. 38(3):715-725, 2003.

Matsui Ji, Haque A, Huss D, Messana EP, Alosi JA, Roberson DW, Cotanche DA, Dickman JD, Warchol ME. Caspase inhibitors promote vestibular hair cell survival and function after aminoglycoside treatment in vivo. J. Neurosci. 23:6111-6122, 2003.

McNally WP, Pool WF, Sinz MW, Dehart P, Ortwine DF, Huang CC, Chang T, Woolf TF. Distribution of tacrine and metabolites in rat brain and plasma after single and multiple-dose regiments. Evidence for accumulation of tacrine in brain tissue. Drug. Metab. Dispos. 24(6):628-633, 1996.

Murakami SL, Cunningham LL, Werner LA, Bauer E, Pujol R, Raible DW, Rubel EW. Developmental differences in susceptibility to neomycin-induced hair cell death in the lateral line neuromasts of zebrafish (Danio rerio). Hear. Res. 186:47-56, 2003.

Окамото M, ONo M, BaвA M. Suppression of cytokine production and neural cell death by the anti-inflammatory alkaloid cepharanthine: a potential agent against HIV-1 encephalopathy. Biochem. Pharmacol. 62(6):747-753, 2001.

Osnes JB, Aass H, Andersen GO, Skomedal T. First-line antihypertensive therapy. Lancet. 356:509-510, 2000.

Ou HC, Raible DW, Rubel EW. Cisplatin-induced hair cell loss in zebrafish (Danio rerio) lateral line. Hear. Res 233:46-53, 2007.

Owens KN, Santos F, Roberts B, Linbo T, Coffin AB, Knisely AJ, Simon JA, Rubel EW, Raible DW. Identification of genetic and chemical modulators of zebrafish mechanosensory hair cell death. PLoS. Genet. 4:e1000020, 2008.

Raible DW, Kruse GJ. Organization of the lateral line system in embryonic zebrafish. J. Comp. Neurol. 421:189-198, 2000.

Richardson GP, Forge A, Kros CJ, Fleming J, Brown SD, Steel KP. Myosin VIIA is required for aminoglycoside accumulation in cochlear hair cells. J. Neurosci 17(24):9506-9519, 1997.

Rizzi MD, Hirose K. Aminoglycoside ototoxicity. Curr. Opin. Otolaryngol. Head. Neck. Surg. 15:352-357, 2007.

Rothstein JD, Patel S, Regan MR, Haenggeli C, Huang YH, Bergles DE, Jin L, Dykes Hoberg M, Vidensky S, Chung DS, Toan SV, Bruijn LI, Su ZZ, GuPTA P, Fisher PB. Beta-lactam antibiotics offer neuroprotection by increasing glutamate transporter expression. Nature. 433:73-77, 2005.
Rowe TC, Chen GL, Hsiang YH, Liu LF. DNA damage by antitumor acridines mediated by mammalian DNA topoisomerase II. Cancer. Res. 46:2021-2026, 1986.

Santos F, Mcdonald G, Rubel EW, Raible DW. Lateral line hair cell maturation is a determinant of aminoglycoside susceptibility in zebrafish (Danio rerio). Hear. Res. 213:25-33, 2006.

SCHACHT J. Aminoglycoside ototoxicity: prevention in sight? Otolaryngol. Head. Neck. Surg. 118:674-677, 1998.

Seiler C, Nicolson T. Defective calmodulin-dependent rapid apical endocytosis in zebrafish sensory hair cell mutants. J. Neurobiol. 41:424-434, 1999.

Sha SH, QIU JH, Schacht J. Aspirin to prevent gentamicin-induced hearing loss. N. Engl. J. Med. 354:1856-1857, 2006.

Steyger PS, Peters SL, Rehling J, Hordichok A, DAi CF. Uptake of gentamicin by bullfrog saccular hair cells in vitro. J. Assoc. Res. Otolaryngol. 4:565-578, 2003.

Sugahara K, Rubel EW, Cunningham LL. JNK signaling in neomycininduced vestibular hair cell death. Hear. Res 221:128-135, 2006.

Ton C, PARng C. The use of zebrafish for assessing ototoxic and otoprotective agents. Hear. Res. 208:79-88, 2005.

Wang J, Van De Water TR, Bonny C, de Ribaupierre F, Puel JL, Zine A. A peptide inhibitor of c-Jun N-terminal kinase protects against both aminoglycoside and acoustic trauma-induced auditory hair cell death and hearing loss. J. Neurosci. 23:8596-8607, 2003.

Wang W, Duan W, Igarashi S, Morita H, Nakamura M, Ross CA. Compounds blocking mutant huntingtin toxicity identified using a Huntington's disease neuronal cell model. Neurobiol. Dis. 20:500-508, 2005.

Watkins P, Zimmerman H, Knapp M, Gracon S, Lewis K. Hepatotoxic effects of tacrine administration in patients with Alzheimer's disease. JAMA. 271(13):992-998, 1994.

Westerfield M. The Zebrafish Book: A Guide for the Laboratory Use of Zebrafish (Danio rerio). Eugene, OR, University of Oregon Press, 2000.

Wierenga D, Eaton C. The drug development and approval process. In Development: New Medicines for Older Americans. Pharmaceutical Manufacturers Association, Washington, DC, 1993.

WikLer M. Methods for Dilution Antimicrobial Susceptibility Tests for Bacteria That Grow Aerobically. Clinical and Laboratory Standards Institute. 1-64, 2006.

WIKLER M. Performance Standards for Antimicrobial Susceptibility Testing. Clinical and Laboratory Standards Institute 1-182, 2007.

Williams JA, Holder N. Cell turnover in neuromasts of zebrafish larvae. Hear. Res. 143:171-181, 2000.

Yu L, Alva A, Su H, Dutt P, Freundt E, Welsh S, Baehrecke EH, LENARDO MJ. Regulation of an ATG7-beclin 1 program of autophagic cell death by caspase-8. Science. 304:1500-1502, 2004.

Zheng JL, GAO WQ. Concanavalin A protects hair cells against gentamicin ototoxicity in rat cochlear explant cultures. J. Neurobiol. 39:29-40, 1999.

ZINE A, VAN DE WATER TR. The MAPK/JNK signalling pathway offers potential therapeutic targets for the prevention of acquired deafness. Curr. Drug. Targets. CNS. Neurol. Disord. 3:325-332, 2004. 